\title{
Digressões: Estratégicas Jnterativas na Contação de Histórias
}

\author{
Rosane Suely Alvares LUNARDELLI \\ Universidade Estadual de Londrina
}

Resumo: Fundamentado em teorias que estudam o texto a partir de
uma perspectiva textual-interativa, este artigo discute a presença de
fragmentos digressivos na Atividade de Contação de Histórias. Com
base na tipologia adotada por Andrade (1995), elaborou-se tabela com
os itens mencionados e suas freqüências, que foram analisadas
qualitativamente. Os resultados dessas análises vêm comprovar a
hipótese inicial de que as digressões são procedimentos lingüísticos
fundamentais à atividade de Contação de Histórias, já que possibilitam
a contextualização dos dados e favorecem, expressivamente, o contato
entre os interlocutores.

Palavras-chave: contação de histórias; digressão; língua falada; interação verbal.

\begin{abstract}
Based on theories that study the text from an interactivetextual point of view, this article deals with the presence of digressive fragments in storytelling activities. Based on the typology adopted by Andrade (1995), charts, which include items that apply to the research in question, and that relate to their frequency, have been created for further qualitative analysis. The result of the analysis confirms the initial hypothesis: that digressions are fundamental as linguistic procedures for storytelling activity.
\end{abstract}

Keywords: storytelling; digression; spoken language; verbal interaction.

Resumen: Con base en teorías que estudian el texto a partir de una perspectiva textual interactiva, este artículo trata de la presencia de fragmentos digresivos en la actividad Hora del Cuento. Con base en la tipología adoptada por Andrade (1995), se elaboró una lista con los itens mencionados y frecuencias, que fueron analisadas cualitativamente. Los resultados de esos análisis comprueban las hipótesis iniciales de que las digresiones son procedimientos lingüísticos fundamentales en 
el recuento de historias, ya que posibilitan la contextualización de los dados y favorecen, expresivamente, el contacto entre los interlocutores. Palabras claves: Hora del Cuento; digresión; lengua hablada; interacción verbal.

\section{Introdução}

A inserção da literatura no universo infantil tem sido valorizada por meio de propostas pedagógicas, literárias, elaboradas por programas governamentais e não-governamentais. A respeito desse tema existe, no Brasil, uma significativa bibliografia produzida por diversas áreas do conhecimento, e nela são enfatizadas muitas das contribuições advindas dessa leitura, sejam elas consideradas em seus aspectos cognitivos, afetivos ou ideológicos.

A literatura infantil, segundo Coellho (2000, p. 27),

é, antes de tudo, literatura; ou melhor, é arte: fenômeno de criatividade que representa o mundo, o homem, a vida, através da palavra. Funde os sonhos e a vida prática, o imaginário e o real, os ideais e sua possível/impossível realização...

Para Garcez (1999, p. 49), a leitura literária infantil é considerada um

instrumento de aprendizagem contínua e auto-educação; aperfeiçoamento geral da linguagem (léxico, sintaxe e semântica); [...] exercício de liberdade; antecipação e ordenamento de experiências emocionais.

Baseando-se na argumentação das Autoras acima citadas, fica evidente que a leitura, a compreensão de textos literários é um dos meios mais eficientes de desenvolvimento sistemático da linguagem e da personalidade, de uma forma lúdica e afetiva, sem apresentar o caráter formal que geralmente caracteriza muitas das atividades desenvolvidas em sala de aula.

Consciente dos benefícios dessas leituras, a escola, entre outros "espaços", busca propiciar o contato prazeroso de seus 
educandos com as obras por meio de algumas atividades, e entre elas, a de Contação de Histórias, nas quais periodicamente são lidas ou narradas histórias para as crianças e que, de acordo com Campos e Bezerra (1988, p. 79), “[...] desenvolvem necessariamente contato com o livro e procuram despertar interesse pela leitura".

Vários autores, entre eles, Bamberger (1995), Coelho (1998), Barcellos e Neves (1995), Sandroni e Machado (1987), são unânimes em assinalar a contribuição da Contação de Histórias. Para eles, ao estabelecer uma ligação entre a fantasia e a realidade, essa prática desenvolve a linguagem oral e escrita, amplia o vocabulário, estimula a imaginação e criatividade e, também, a capacidade de dar seqüência lógica aos fatos. Além disso, ela constitui um estímulo à instauração do gosto pela leitura.

De acordo com Abramovich (1997, p. 17)

É ouvindo histórias que se pode sentir (também) emoções importantes, como a tristeza, a raiva, a irritação, o bem-estar, o medo, a alegria, o pavor, a insegurança, a tranqüilidade, e tantas outras mais, e viver profundamente tudo o que as narrativas provocam em quem as ouve - com toda a amplitude, significância e verdade que cada uma delas fez (ou não) brotar ...

De acordo com esse quadro de valorização da narrativa oral, é justificada a relevância e a necessidade de estudos que privilegiem, sob a ótica das diversas áreas do conhecimento, a Contação de Histórias. Entretanto, detecta-se, no âmbito da Lingüística, a escassez de estudos que investiguem, entre outros tantos aspectos, os processos interacionais subjacentes aos textos falados utilizados nessa atividade.

Verificada a presença e a importância da leitura na vida do ser humano, é na infância que se dá o primeiro contato que, em muitos casos, será fundamental ao estabelecimento ou não do gosto literário. Discorrendo a esse respeito, Sandroni e Machado ressaltam a estreita relação entre a convivência da criança com textos literários e a formação de leitores ao argumentarem que "os resultados têm sido significativos, uma vez que as crianças, estimuladas pela história, se interessam em ler outros livros, conhecer autores novos [...]" (1987, p. 36). 
A familiarização e o gosto pela literatura deveria ser um processo iniciado no lar e sedimentado nos anos subseqüentes, nos espaços formais de ensino. Porém, como afirma Varlotta, "a realidade de nossas escolas públicas [e particulares] é que poucas crianças, hoje, trazem para a escola a experiência de contatos com textos escritos ou mesmo com histórias contadas" (1987, p. 35).

Devido a alguns fatores de ordem sócio-econômica, como por exemplo, a não valorização da leitura, a baixa renda inviabilizando a aquisição de livros, entre outros, muitas famílias não têm desempenhado seu papel de agente promotor da leitura e transferem para a escola e outras organizações, atribuições que deveriam ser suas. Estas instituições assumem, então, a dupla responsabilidade de incentivar em seus alunos ou ouvintes, o gosto pela leitura, além de proporcionar-lhes condições para que possam realizar leituras proficientes nos mais diversos tipos de textos, sejam eles de caráter científico, técnico, pragmático ou poético.

Com o intuito de promover o interesse e o desenvolvimento das habilidades necessárias à leitura e apreciação de textos literários, algumas escolas, reitere-se, realizam, entre outras atividades, a Hora do Conto ou Contação de Histórias com crianças de $1^{a}$ a $3^{a}$ série e, eventualmente, com a $4^{a}$ série do ensino fundamental. Porém se verifica, da parte de muitas escolas, uma atitude dúbia e contraditória: ao mesmo tempo em que essas instituições apregoam a importância da leitura literária, a Contação de Histórias na maioria das vezes, é realizada de uma forma intuitiva, sem embasamento teóricometodológico específico. Observa-se, nesses casos, que muitas escolas delegam essa tarefa às pessoas que trabalham em outro setor da instituição ou que não estão preparadas para realizá-las. Pois, como afirma Coelho (1998, p. 13), "Nem toda história vem no livro pronta para ser contada. A linguagem escrita, por mais simples e acessível, ainda requer a adaptação verbal que facilite sua compreensão e a torne mais dinâmica, mais comunicativa."

Dada a importância de que se reveste o ato de contar histórias para as crianças, ele não pode restringir-se à oralização de um texto escrito, sem a preocupação do "como" contá-las, que estratégias utilizar, entre muitos outros fatores.

A linguagem da Contação de Histórias apresenta os fenômenos característicos da língua falada (pausas, truncamentos, 
repetições e outras formas de reiteração). Dentre esses fenômenos, foram selecionadas, neste estudo, as digressões, por sua importância na citada forma de atividade verbal.

\section{Digressão}

Embora rejeitadas pela língua escrita padrão, a digressão é um fenômeno recorrente na língua falada e pode ser definida como um trecho da conversa que não se acha topicamente relacionada com o material conversacional imediatamente precedente, nem com o que está imediatamente depois. Apesar de considerada como um desvio do tópico que vinha sendo desenvolvido, ela assegura continuidade no fluxo da conversação. As digressões, é possível afirmar, contribuem efetivamente para a manutenção do diálogo.

Andrade (1995, p. 287) caracteriza a digressão como "uma estratégia por meio do qual os interlocutores conduzem o texto falado" [...]. Embora ela constitua um "elemento suspensivo e flutuante: 'excesso' ou desvio momentâneo [...] traz vivacidade ao jogo textualinterativo e permite um envolvimento maior dos participantes". Posteriormente, em outro trabalho (2000, p. 100), a Autora afirma que a digressão, quando analisada sob o enfoque interacional, "passa a funcionar como uma estratégia por meio da qual se busca um determinado efeito de sentido", devendo ser considerada como um valioso componente do mecanismo textual no que tange à condução do tópico discursivo.

Os trechos digressivos, vale salientar, não provocam descontinuidade no fluxo conversacional. Objetivando a coerência conversacional, os falantes se utilizam de elementos coesivos (marcadores e repetições), para voltar ao tópico anterior logo após o segmento digressivo. Em muitos casos, porém, pode haver o retorno ao tópico principal sem o uso desses procedimentos.

No esquema abaixo, tem-se a digressão entre a $2^{\mathrm{a}}$ e $3^{\mathrm{a}}$

etapas:

$$
\begin{aligned}
& 1^{a} \text { etapa }- \text { retirada do tópico A } \\
& 2^{a} \text { etapa - introdução do tópico B } \\
& 3^{a} \text { etapa }- \text { retirada do tópico B } \\
& 4^{a} \text { etapa - reintrodução do tópico A }
\end{aligned}
$$


Baseando-se nas asserções formuladas por Dascal e Katriel (1982), Andrade (1995), apresenta três tipos de digressão:

a) Digressão lógico-experencial, anteriormente denominada digressão baseada no enunciado, "estabelece certo propósito de natureza pessoal entre o tópico central e o digressivo" (p. 169). Revestem-se de funções demonstrativas, exemplificadoras, ilustrativas, sendo utilizadas para evidenciar o ponto de vista do falante, por meio de exemplos, argumentações, entre outros aspectos. Geralmente esse fenômeno é incluído ou encerrado por marcadores conversacionais como: por falar nisso..., a propósito... , já que você mencionou isso..., voltando ao assunto.....

b) Digressão interpessoal, anteriormente - digressão baseada na interação - ao contrário das outras digressões, não apresenta relações de conteúdo com o tópico em andamento. "Entretanto, não pode ser considerada disfuncional no que se refere ao fluxo conversacional". (p. 101). Determinada por fatores de ordem contextual, subdivide-se em digressão interpessoal incidental e digressão interpessoal imediata. A incidental resulta das preocupações de ordem social, da necessidade de seguir as regras pré-estabelecidas em seu meio. Caracteriza-se por sua função participatória, integralizadora, na medida em que é utilizada para integrar um novo interlocutor na atividade interacional. $A$ digressão interpessoal imediata, por sua vez, está relacionada ao desejo do falante de, num dado momento, incluir na situação discursiva elementos contextuais que estavam à margem, tais como palavras de agradecimentos quando alguém oferece algo para beber ou comer, por exemplo.

Sua função principal é atributiva, uma vez que um dos interlocutores atribui valor a um elemento extrínseco, tornando-o partícipe da situação discursiva.

c) Digressão retórica, denominada digressão baseada em seqüência inserida, institui um vínculo de pertinência discursiva, contribuindo para "a textura da produção lingüística" (p. 170). Subdivide-se em digressão retórica didática e digressão retórica persuasiva. A digressão retórica didática estabelece momentaneamente uma interrupção no fluxo discursivo, causada pela preocupação de um dos participantes em manter a interação. Esses cuidados deixam entrever uma preocupação com o modo lingüístico do discurso. Muito utilizada pelos falantes, diz respeito a uma variedade de atos de fala corretivos, explicativos entre outros. Essencialmente elucidativa, a digressão retórica didática é habitualmente utilizada em espaços e situações didáticas. 
A digressão retórica persuasiva "revela uma certa manipulação da pergunta, orientando-a de alguma maneira" (ANDRADE, 1995, p. 170). Encontradas em debates ou entrevistas quando um dos locutores faz uma pergunta, não para solicitar qualquer esclarecimento, mas para manipular seu interlocutor. Entretanto, essa manipulação só pode ser percebida se forem observadas as pistas de contextualização deixadas no encaminhamento do tópico discursivo em andamento, tais como: entonação, perguntas manipulatórias que provocam pausa no fluxo informacional.

De acordo com essa linha de raciocínio, foram realizadas descrições e análises qualitativas do material coletado em situações reais de interação, ou seja, em uma atividade de Contação de História realizada em uma escola da rede privada (escola A) e uma escola da rede municipal (escola $\mathrm{B}$ ), com alunos da terceira série do ensino fundamental. A história contada pelas professoras foi Ali Babá e os Quarenta Ladrões, extraída da coletânea As mil e Uma Noites, adaptada por Ruth Rocha e publicado pela editora FTD em 1994.

As ocorrências de segmentos digressivos, apresentadas sob a forma de quadros, foram analisadas quanto à sua tipologia.

\section{Análise das Digressões quanto à sua Tipologia}

Quadro 1 - Tipos de Digressão

\begin{tabular}{|c|c|c|}
\hline Digressão & $\begin{array}{c}\text { Escola A - } \\
\text { frequência }\end{array}$ & $\begin{array}{c}\text { Escola B - } \\
\text { frequência }\end{array}$ \\
\hline $\begin{array}{c}\text { a) Lógico- } \\
\text { Experencial }\end{array}$ & 8 & 5 \\
\hline $\begin{array}{c}\text { b) Interpessoal - } \\
\text { incidental }\end{array}$ & 9 & 9 \\
\hline c) Retórica Didática & 34 & 10 \\
\hline
\end{tabular}




\section{a) Digressão Lógico-Experencial}

O segmento digressivo denominado lógico-experencial (baseado no enunciado), como já se viu anteriormente, apresenta relação de conteúdo com o enunciado principal. $\mathrm{O}$ trecho a seguir, extraído da atividade realizada na escola municipal, estabelece, de maneira muito clara, "certo propósito de natureza pessoal entre o tópico central e o digressivo" (ANDRADE, 1995, p. 169).

Contextualização: A contadora expressa sua opinião a respeito da atitude do ministro em relação à Sherazade:

... a filha DELE é uma moça bonita e inteligente ${ }^{1}$ não claro que o primeiro ministro que era o pai da moça não ia escolher ela para casar com o rei por que sabia que ela iria morrer não é verdade Paulinho.... bem então

Observa-se que o tópico em andamento é momentaneamente suspenso e um outro que estava à margem (opinião do falante) é introduzido. Essa suspensão tópica, apesar de interromper a seqüência narrativa, relaciona-se com o conteúdo informativo do texto e, assim, permite a inserção dos dados no universo cognitivocontextual dos alunos. Dessa forma, não há descontinuidade no fluxo conversacional, aliás, essa modalidade de digressão é importante sob o ponto de vista interacional.

Um outro exemplo: no final da atividade, quando as crianças estão se manifestando a respeito de que momento mais gostaram, um aluno pergunta à professora qual é o significado de apunhalar.

P - ah: :: que ela fez as cruzinhas inteligente ela né" [[huhum]] e por quê? [[o que é apunhalar]]apunbalar" é pegar um punhal [[bum]] e espetar na pessoa dai faz. um corte sai sangue e a pessoa fica muito ferida pode até morrer sabe "apunhalar[[ ab! Entendi]]é enfiar o punbal e você Aline qual parte você mais gostou"

$\mathrm{Na}$ explicação dada acerca do significado da palavra apunhalar, verifica-se que a professora traz, para o evento, dados que são próprios do seu universo conceitual e referencial, visando influenciar a elaboração do contexto situacional no seu interlocutor, em função de suas metas comunicativas.

\footnotetext{
${ }^{1}$ As digressões, em todo o texto, serão destacadas em itálico. A letra P indica que o falante é a professora; T é a turma e A é um aluno.
} 
A freqüência da utilização da digressão lógico-experencial, um pouco menor do que os outros tipos de digressões encontradas está relacionada à função exemplificadora, porém de caráter pessoal ou do próprio universo referencial da contadora de história que não foram consideradas relevantes naqueles momentos. Ou seja, acreditase que a professora não sentiu necessidade de tecer um comentário particular a respeito de algo colocado no tópico prévio ou de tornar mais concreto seu ponto de vista.

\section{b) Digressão Interpessoal Incidental}

A Digressão Interpessoal está vinculada a preocupações de ordem interacional, como, por exemplo, o desejo de integrar os interlocutores no evento conversacional. Embora tenha ocorrido a suspensão temporária do tópico, nota-se que ela não provoca uma quebra na interação e, conseqüentemente, na configuração textual. As referidas digressões subdividem-se em incidental e imediata, porém, no corpus pesquisado, foram encontradas somente ocorrências da digressão incidental, cuja característica integralizadora é um importante indicador do desejo da contadora de estimular e manter a interação.

Contextualização: Ao relatar o momento em que Cassim pronuncia as palavras mágicas para abrir a porta da caverna, a professora incentiva os alunos a participarem da contação.

$\mathrm{P}$ - é ::: ainda não quando ele chegou lá ele lembrava das palavras né vocês me ajudam como que eram as palavras ele parou em frente do rochedo levantou os braços e ele falou ...

Em outro trecho, quando a professora afirma que as crianças são curiosas como Ali Babá, ela cria uma situação de empatia entre o personagem e as crianças, beneficiando, ainda mais, a interação.

P - ...QUAren::ta puxa' é verdade saíram to-dos os ladrões' e o Ali Babá era muito curioso vocês são curiosos também

$\mathrm{T}$ - so::mos::

P - o Ali Babá não fez outra coisa muito curioso chegou bem no mesmo lugar ...

A supressão dos segmentos digressivos, nos trechos apontados, é fato, não causaria nenhum dano à coerência textual, porém, com certeza, prejudicaria a comunicação (interação), essenciais à realização da atividade. 


\section{c) Digressão Retórica Didática}

A Digressão Retórica Didática, segundo Andrade (2000), está relacionada a uma grande variedade de atos de fala esclarecedores, corretivos, entre outros. Caracteriza-se por uma espécie de pausa no fluxo conversacional, ocasionada pela necessidade de o interlocutor obter, naquele momento, um esclarecimento ou uma informação. Nos trechos seguintes, têm-se digressões retóricas didáticas, já que o falante procura estabelecer um vínculo de pertinência textual, objetivando "contribuir para a textura da produção lingüística, instaurando no contexto situacional elementos relevantes ao contexto cultural, biográfico individual ou de conhecimento de mundo" (ANDRADE, 2000, p. 114).

Contextualização: A professora explica uma das finalidades da utilização do azeite naquela época.

P - ... acabou o azeite que: :: a : :::naquele tempo não existia lur elétrica então eles tinham assim uns (incompreensível) com azeite e uma vela que era alimentada por aquele azeite pra iluminar o ambiente e a Morgiana...

Observa-se, no exemplo acima, que há uma mudança em relação ao foco, sem, no entanto, provocar uma ruptura na atividade dialógica. Este tipo de movimentação tópica é muito comum e demonstra uma característica contextualizadora importante, já que responde a um tipo de questão que aflora no momento. É necessário ressaltar que a contextualização dos dados, ao propiciar esclarecimentos a respeito de algo dito e que não ficou claro, promove a interação, a interlocução.

Veja-se a seguir outro segmento digressivo retórico didático: Ao mesmo tempo em que esclarece onde é que a escrava havia despejado o azeite, a professora dirige-se à classe, buscando o seu envolvimento:

$\mathrm{P}$ - ela pegon aquele grande saco de azeite levou até à cozinha levou até o fogão pôs bastante lenha lá e ferveu aquele az̧eite $(+)$ trouxe aquele azeite fervendo

A - é:: e colocou em cada burrinho

P - i::sso ... em cada burrinho não em cada saco [[ saco:: ]] i::sso é verdade vocês já viram esse filme sim hein? bem ela abriu cada saco e foi...

No exemplo acima, evidencia-se uma pausa no fluxo da informação, ocasionada pelo cuidado da professora em explicitar como 
e onde foi armazenado o azeite fervendo. Para Andrade essa estratégia lingüística é bastante utilizada "e revela uma característica interacional importante, visto que ela pode servir tanto para esclarecimento, como para manipulação da pergunta, orientando-a de alguma forma." (1995, p. 105).

Na história contada, a utilização de segmentos explicativos (digressão retórica didática), está estreitamente relacionada com a finalidade maior do espaço escolar que é o de instruir, ensinar. Além disso, as contadoras das histórias são professoras e, como tal, assumem seus papéis de mediadoras do conhecimento. De acordo com a tabela apresentada, verificou-se um grande número de ocorrências deste tipo de digressão em uma das histórias contadas (escola A). É possível atribuir esse fato ao desconhecimento de vários alunos pela história, tornando necessária a intervenção da professora por meio de inserções de fragmentos esclarecedores.

\section{Comentários Conclusivos}

O texto falado compõe-se de várias porções tópicas que, apesar de organizadas seqüencialmente, podem ser retomadas. Quando estes tópicos se apresentam em uma seqüência linear, há uma continuidade tópica, porém, quando um tópico é suspenso e reintroduzido em um outro momento, tem-se uma descontinuidade tópica, que é o traço definidor do fenômeno da digressão. Essa descontinuidade, entretanto, não ocasiona interrupção no fluxo conversacional, pois os interlocutores, procurando assegurar a progressão textual, utilizam, entre outros recursos, marcadores conversacionais para introduzir o trecho digressivo, ou para retomarem o tópico central. Em muitos casos, porém, empregam-se digressões sem o uso desses mecanismos.

As digressões, porções textuais que provocam uma suspensão no tópico em andamento, estabelecem uma nova focalização tópica. Com isso, evidencia-se então algo que estava no horizonte do campo de percepção do falante, isto é, desloca-se o foco para um propósito (assunto) de natureza pessoal (digressão lógico-experencial), propósito de natureza contextual (digressão interpessoal incidental e digressão interpessoal imediata) ou de natureza textual (digressão retórica didática e digressão retórica persuasiva). 
A digressão retórica didática foi a mais utilizada no evento interativo observado. A presença de um número significativo de ocorrências desse tipo está relacionada com o contexto em que a atividade está inserida: um espaço essencialmente educativo, instrutivo. Cabe relembrar que o contexto ou a realidade que envolve uma atividade verbal contribui de maneira efetiva para a escolha do tipo de digressão. A digressão retórica didática, conforme apresentada, diz respeito a uma gama de atos de fala corretivos, informativos, muito utilizados em uma atividade de contação de histórias e que, por sua vez, contribuem para o pleno estabelecimento e manutenção da interação.

Nesse sentido, é possível verificar que a digressão, estratégia conversacional muito utilizada pelo falante, deve ser considerada como um evento coerente, que acrescenta, à atividade dialógica, elementos de base informacional e interacional. Com isso, ela passa a intervir de forma decisiva na instauração, condução e manutenção da organização textual e interacional do evento comunicativo.

\section{Referências Bibliográficas}

ABRAMOVICH, Fanny. Literatura Infantil: gostosuras e bobices. 5. ed. São Paulo: Scipione, 1997.

ANDRADE, M. L.da C.V. de O. A digressão como estratégia discursiva na produção de textos orais e escritos. In: PRETI, Dino. (Org.). Fala e escrita em questão. São Paulo: Humanitas Publicações FFLCH/USP. 2000. p. 99-128. (Projetos Paralelos- NURC/ S.P. , 4)

Digressão: uma estratégia na condução do jogo textualinterativo. 1995. Tese (Doutorado em Semiótica e Lingüística Geral) Faculdade de Filosofia, Letras e Ciências Humanas da USP, São Paulo.

BAMBERGER, Richard. Como incentivar o hábito da leitura. 6. ed. São Paulo: Cultrix, 1995.

BARCELLOS, Gládis Maria Ferrão; NEVES, Iara Conceição Bittencourt. Hora do conto: da fantasia ao prazer de ler. Porto Alegre: Sagra - D. C. Luzzatto, 1995. 
BROWN, G.; YULE, G. Discourse analysis. Cambridge: Cambridge University Press, 1983.

CAMPOS, Cláudia de Arruda; BEZERRA, M.de Lourdes Leandro. A Hora da História. Cadernos de Pesquisa, São Paulo, n. 65, p. 7885, maio 1988.

COELHO, Betty. Contar histórias: uma arte sem idade. 8. ed. São Paulo: Ática, 1998.

COELHO, Nelly Novaes. A literatura infantil: história, teoria, análise. São Paulo: Moderna, 2000.

DASCAL, M.; KATRIEL, T. Digressions: a study in conversational coherence. In: PETÖFI, J.S. (ed.). Text vs. Sentence. Hamburg, Buske, v.29, p. 76-95, 1982.

GARCEZ, L.H. do Carmo. A leitura compartilhada na hora do conto. In: VIANNA, M.M.; CAMPELlO, B.; MOURA, V.H. BIBLIOTECA ESCOLAR: espaço de ação pedagógica. Belo horizonte: Escola de Biblioteconomia da UFMG, 1999. p. 49-59.

SANDRONI, Laura C.; MACHADO, Luiz R. (Orgs.). A criança e o livro: guia prático de estímulo à leitura. 2. ed. São Paulo: Ática, 1987. (Série Educação em Ação)

URBANO, H. Oralidade na literatura: o caso Rubem Fonseca. São Paulo: Cortez, 2000.

VARLOTTA, Y.M da C. L. Literatura Infantil nas séries iniciais: desafio à reflexão ou possibilidade de trabalho? Leitura: Teoria \& Prática, Campinas, a. 6, n. 9, p. 33-42, jun. 1987. 